\title{
A casualty psychiatric clinic at the Royal Liverpool Hospital
}

\author{
Hadrian N. Ball, Registrar, Rainhill Hospital, Prescot, Merseyside (correspondence) \\ and Michael I. LeVI, Senior House Officer, Rainhill Hospital
}

Clinical experience suggests that accident and emergency departments are increasingly adopting the role of primary health care providers, particularly those departments situated within the inner cities. Previous studies have shown that there is a high rate of psychiatric morbidity contained within the group of patients attending accident and emergency departments. ${ }^{1}$ The question arises as to how adequate provision for serving such patients can be made. Traditionally these patients have been referred to a duty psychiatrist for assessment or have been discharged from the department without a specialist psychiatric opinion having been sought. This approach has its drawbacks as an inappropriate emergency referral creates unnecessary work for an already busy duty psychiatrist. On the other hand no referral at all may result in serious psychiatric disorder remaining undetected and untreated with possible tragic consequences.

It has been argued that there should be a restriction of the boundaries of psychiatry so that the profession should only concern itself with the well defined syndromes that it can treat. ${ }^{2}$ Alternatively, services have been developed which allow easy access to care professionals for all individuals experiencing emotional or social distress. Examples include the Maudsley Walk-In Clinic ${ }^{3}$ and the Eastgate Community Mental Health Centre. ${ }^{4}$ These particular projects allowed direct access of the service to individuals requesting help. At the Royal Liverpool Hospital, we have attempted to provide a casualty department based psychiatric service specifically designed for the group of patients previously mentioned.

\section{The clinic}

The Royal Liverpool Hospital is a major teaching hospital located at the centre of an economically deprived city. As would be expected, the accident and emergency $(A / E)$ department of this hospital is an extremely busy unit with a high input of cases requiring psychiatric assessment.

The weekly casualty psychiatric clinic was first held in January 1983. Patients are referred by the A/E staff and assessed by psychiatric trainees under the supervision of a consultant psychiatrist. The aim is to provide a psychiatric opinion and a set of referral criteria were outlined for that purpose:

(1) non-urgent;

(2) long-standing problems with transient worsening or sudden decision to request help;
(3) alcohol problems;

(4) physical symptoms for which there appears to be an underlying psychiatric problem;

(5) psychiatric problems giving concern to the casualty officer;

(6) patients insisting on discharge before a psychiatric opinion can be obtained;

(7) patients referred after telephone discussion with psychiatrist on-call.

It follows that the psychiatric liaison service provided for the $A / E$ department has two components, an emergency 'on-call' service, and the casualty clinic for the group of patients previously defined. In the assessment of the value of such a clinic the following points require consideration: (a) How is the clinic being used by the A/E medical staff? Are the characteristics of referred patients those that would be expected by adherence to the referral criteria? (b) What happens to those referred patients in terms of attendance rates and disposal?

With reference to the referral criteria we would expect the following to be true of the clinic sample compared with those referred directly to the duty psychiatrist for an emergency consultation:

(i) a lesser proportion of patients suffering from major mental disorders: psychosis and organic states;

(ii) a greater proportion of patients with alcoholrelated difficulties;

(iii) an increased rate of self-referral to the $\mathrm{A} / \mathrm{E}$ department in the clinic cases;

(iv) a higher rate of previous attendance at the $\mathrm{A} / \mathrm{E}$ department; and

(v) but major differences would not occur in terms of sex, age, time of attendance.

In an attempt to evaluate the role of the clinic, a retrospective analysis of the case notes was undertaken.

\section{The study}

Patients over a three month period (October to December 1986) were studied. The following data were obtained from their casualty and psychiatric notes: age, sex, time of attendance at the A/E department, source of referral, diagnosis, the attendance rate to the A/E department (for any reason) during the 12 months prior to the index consultation, and mode of disposal. 
TABLE 1

The diagnostic categories within the two groups of patients

\begin{tabular}{lrcccc}
\hline & $\begin{array}{c}A / E \\
\text { patients } \\
(n=112)\end{array}$ & $\begin{array}{c}\text { Clinic } \\
\text { patients } \\
(n=38)\end{array}$ & $(P<)$ \\
\hline & No. & $\%$ & No. & $\%$ & \\
\hline Organic disorder & 4 & 3.64 & 0 & 0.00 & NS \\
Psychoses & 27 & 24.55 & 0 & 0.00 & 0.001 \\
Depressive illness & 17 & 15.45 & 8 & 24.23 & NS \\
Neurotic disorder & 13 & 11.63 & 6 & 18.12 & NS \\
Personality disorder & 15 & 13.63 & 2 & 6.06 & NS \\
Drug/alcohol & & & & & \\
$\quad$ related disorders & 12 & 10.91 & 9 & 27.27 & NS \\
$\begin{array}{l}\text { Miscellaneous } \\
\text { Data not known }\end{array}$ & 22 & 20.00 & 7 & 21.21 & 0.05 \\
\hline
\end{tabular}

\section{Results}

During the three months, 112 patients (61 men and 50 women) were referred to the duty psychiatrist, and 38 patients ( 23 men and 15 women) to the clinic. The difference between the two groups was not statistically significant. There were no differences either in terms of age. Most patients in both groups $(72 \%$ of the $\mathrm{A} / \mathrm{E}$ group, $74 \%$ of the clinic group) referred themselves to the hospital. The remainder were referred by their GP, Police or other agencies.

There were significantly less psychoses and more alcohol-related disorders referred to the psychiatric casualty clinic. (Table I).

Comparing the time of attendance at the $A / E$ department for the index consultation, there was no significant difference between the two groups. Over $50 \%$ of patients in both groups attended 'out of hours' i.e. between 1700 hours and 0900 hours. Patients referred to the casualty clinic had attended the A/E department on significantly more occasions than had the group of $\mathrm{A} / \mathrm{E}$ patients, during the 12 months prior to the index consultation.

Of the 38 clinic patients only 18 attended for their appointment. Significantly more of the clinic patients were referred back to the care of their GPs rather than receiving an admission or a psychiatric outpatient appointment.

\section{Discussion}

Most of the 150 patients studied had a formal psychiatric diagnosis attached to them either by a casualty doctor or a trainee psychiatrist. It was a minority that were placed within the 'miscellaneous' group since they did not fit into the formal diagnostic sections. This suggests that patients attending the $\mathrm{A} / \mathrm{E}$ department have a high rate of genuine psychiatric morbidity rather than that an increase in resources leads to an expansion of the boundaries of psychiatry with a consequent increase in utilisation of services. ${ }^{5}$

The casualty clinic was designed for a group of patients with considerable psychiatric morbidity. The results of our study show that such a group exists. The original referral criteria, although vague, predicted with a fair degree of accuracy the characteristics of the patients that the clinic would cater for.

The question of whether the clinic is serving its intended population well is more complex. It could be argued that if the clinic did not exist, their patients would be referred to the duty psychiatrist and an 'on the spot' opinion provided. However, apart from this being an abuse of an 'on-call' service which is supposed to be emergency in nature, the following points would require consideration. Firstly, would the pre-clinic casualty records reveal any differences in the pattern of emergency psychiatric referral from the casualty medical staff? Secondly, how do the rates of non-attendance compare with a typical Royal Liverpool Hospital out-patient clinic?-i.e. there are factors other than those intrinsic to the clinic that require further elucidation.

It cannot be argued that because nine out of every ten patients assessed are referred back to their GP that the clinic is not providing a service. The patients who attend do at least receive a psychiatric opinion. It should be remembered that the clinic was only designed to offer an opinion and the possibilities following this are limited, i.e. referral to an out-patient department or discharge to the GP who may then refer to an out-patient clinic if he so desires. An interesting proposal would be to introduce follow-up facilities within the clinic which would then offer treatment and support services to this subculture of patients in Liverpool's centre. Would such a facility then lead to increased rates of attendance? Furthermore, it is difficult to measure what any patient actually receives from a single psychiatric interview.

This study shows that a group of patients can be catered for by a psychiatric casualty clinic. The high rate of non-attendance does not necessarily indicate that such a clinic is providing a poor service. Further research is needed however in order to determine factors associated with this non-attendance.

\section{References}

'Summers, W., Rund, D. \& Levin, M. (1979) Psychiatric illness in a general urban emergency room: daytime versus night time population. Journal of Clinical Psychiatry, 40, 340-343.

${ }^{2}$ Richman, A. \& BARRY, A. (1985) More and more is less and less - the myth of massive psychiatric need. British Journal of Psychiatry, 146, 164-168.

${ }^{3}$ MeNG HoI, Lim (1983) A psychiatric emergency clinic-a study of attendances over six months. British Journal of Psychiatry, 143, 460-466.

${ }^{4}$ Hutron, F. (1985) Self-referrals to a community mental health centre: A 3 year study. British Journal of Psychiatry, 147, 540-544.

${ }^{5}$ GeIL, R. (1980) The truth about psychiatric morbidity? Acta Psychiatrica Scandinavia, 62 (Supp. 285), 30-40. 